\title{
History of health technology assessment in Belgium
}

\author{
Irina Cleemput \\ Belgian Health Care Knowledge Centre and K.U.Leuven \\ Philippe Van Wilder \\ National Institute for Health and Disability Insurance
}

\begin{abstract}
Objectives: This paper gives an overview of health technology assessment (HTA) in Belgium.

Methods: The information included in the overview is based on legal documents and publicly available year reports of the Belgian Health Care Knowledge Centre (KCE). Results: Belgium has a relatively young history in HTA. The principle of evidence-based medicine (EBM) was introduced in the drug reimbursement procedure in 2001, with the establishment of the Drug Reimbursement Committee (DRC). The DRC assesses the efficacy, safety, convenience, applicability, and effectiveness of a drug relative to existing treatment alternatives. For some drugs, relative cost-effectiveness is also evaluated. The activities of the DRC can, therefore, be considered to be the first official HTA activities in Belgium. Later, in 2003, KCE was established. Its mission was to perform policy preparing research in the healthcare and health insurance sector and to give advice to policy makers about how they can obtain an efficient allocation of limited healthcare resources that optimizes the quality and accessibility of health care. This broad mission has been operationalized by activities in three domains of research: HTA, health services research, and good clinical practice. KCE is independent from the policy maker. Its HTAs contain policy recommendations that may inform policy decisions but are not binding.

Conclusions: Although the Belgian history of HTA is relatively short, its foundations are strong and the impact of HTA increasing. Nevertheless KCE has many challenges for the future, including continued quality assurance, further development of international collaboration, and further development of methodological guidance for HTA.
\end{abstract}

Keywords: Technology assessment, Biomedical, Insurance, Health, Reimbursement, Belgium

Belgium has a relatively recent history of health technology assessment (HTA). HTA first found its introduction in the domain of the pharmaceuticals, in the context of the assessment of the appropriateness of reimbursement of drugs. The Drug Reimbursement Committee (DRC) developed procedures for the evaluation of drugs to prepare an advice for the minister of social affairs. It was only a couple of years later that the assessment of other health technologies was organized at the semigovernmental level with the es-

The authors thank Jean-Pierre Closon and Gert Peeters for reviewing the paper and Gudrun Briat for providing the statistics on KCE's staff and reports. The authors did not receive funding for writing this manuscript. tablishment of the Belgian Health Care Knowledge Centre (KCE).

\section{THE DRUG REIMBURSEMENT COMMITTEE}

\section{Establishment and Legal Entity}

The Drug Reimbursement Committee (DRC) was established in 2001, with the Royal Decree of December 21, 2001, as the committee who is in charge of applying the modified reimbursement procedure, including the transparent use of evidence-based medicine (EBM) methods in the evaluation of pharmaceuticals (2). The mission, organization, and 
procedures of the DRC can, therefore, not be considered separately from the drug reimbursement procedure in Belgium.

Submissions for Market Authorization Application (MAA) for medicines for human use are regulated within the European Union (EU) (4). Regarding reimbursement submissions, however, individual member states are competent (3). Obtaining reimbursement is often considered the "fourth hurdle" for the marketing of drugs.

The EU legal basis is the Transparency Directive (3), which states that pricing and reimbursement decisions must be taken in a transparent, objective, and verifiable way within strict time limits (maximum of 180 days from submission to decision). The DRC started its activities on January 1, 2002.

\section{Mission}

The actual reimbursement procedure was implemented with the aim to reduce timelines and to adopt EBM principles to enhance transparency and use of objective criteria. The use of pharmacoeconomic criteria makes it possible to address efficiency concerns.

\section{Organization}

For the reimbursement of medicines, the initiative is taken by the relevant pharmaceutical company who must submit a reimbursement file to the Secretary of the DRC. The Belgian reimbursement submissions may be classified according to the individual product claim made by the applicant. The main categories are as follows: new product with added value $(=$ class 1$)$ or with similar value (= class 2$)$, new orphan product, existing medicinal product with request for new indication, and generic medicinal product.

Each submission must be documented by the applicant with the necessary administrative and scientific documents and is evaluated by the DRC. The DRC will evaluate the therapeutic value of the submitted medicine for all submissions except generic ones.

There are five criteria for the evaluation of the therapeutic value of a medicine: efficacy, safety, convenience, applicability, and effectiveness. For each of these criteria the submitted compound will be compared with existing treatment alternatives. Added value is in the actual legislation only applicable to new products claiming class 1 and not to new indications for existing products. Granting an added therapeutic value is a yes-no decision by the DRC. It is only granted if there is at least one positive superiority trial on primary end points against an active control or against a placebo control if there is no alternative. A price premium can only be given if class 1 is granted. Within 180 days, the Minister takes a reimbursement decision based upon the advice of the DRC: the Minister can only deviate from the advice of the DRC by a motivated decision based on social or budgetary reasons.
Table 1. Flowchart of the DRC Procedure

\begin{tabular}{|c|c|c|}
\hline Phase & Step & Action and timeline \\
\hline \multirow[t]{4}{*}{1} & 1 & $\begin{array}{l}\text { Market Authorization is mandatory. Positive } \\
\text { advice from the Committee for Medicinal } \\
\text { Products for Human Use (CHMP) is } \\
\text { sufficient to start reimbursement procedure } \\
\text { in some cases. }\end{array}$ \\
\hline & 2 & $\begin{array}{l}\text { Submission of reimbursement request file / } \\
\text { start of the procedure. }\end{array}$ \\
\hline & 3 & $\begin{array}{l}\text { Brief overview report by day } 30 \text { on product } \\
\text { characteristics. }\end{array}$ \\
\hline & 4 & $\begin{array}{l}\text { In-depth evaluation report on therapeutic } \\
\text { value by day } 60 ; \text { presentation, discussion, } \\
\text { and approval in plenary session of DRC. } \\
\text { Evaluation report sent to applicant who } \\
\text { must reply within } 20 \text { days. }\end{array}$ \\
\hline \multirow[t]{2}{*}{2} & 5 & $\begin{array}{l}\text { Draft proposal of the DRC on reimbursement } \\
\text { modalities by day } 120 \text {; presentation, } \\
\text { discussion, and approval in plenary session } \\
\text { of DRC. Proposal sent to applicant who } \\
\text { must reply within } 10 \text { days. Possibility to } \\
\text { request a hearing for applicant in case of } \\
\text { class } 1 \text { claim. }\end{array}$ \\
\hline & 6 & $\begin{array}{l}\text { Final proposal of the DRC on reimbursement } \\
\text { modalities by day 150; presentation, } \\
\text { discussion, and approval in plenary session } \\
\text { of DRC. Proposal sent to applicant and } \\
\text { Minister. }\end{array}$ \\
\hline \multirow[t]{3}{*}{ Post- DRC } & 7 & $\begin{array}{l}\text { Advice of financial and budget administration. } \\
\text { Decision of Minister by day } 180 \text {. }\end{array}$ \\
\hline & 8 & $\begin{array}{l}\text { Publication of the positive decision in the } \\
\text { Official Journal "Belgisch } \\
\text { Staatsblad/Moniteur Belge". }\end{array}$ \\
\hline & 9 & Decision in application. \\
\hline
\end{tabular}

DRC, Drug Reimbursement Committee.

\section{Working Procedures}

The flowchart of the DRC-procedure, as extracted from Van Wilder \& Dupont (5), is presented in Table 1.

The two-phases procedure is crucial to disentangle the decision on the relative therapeutic value of a medicine from any reimbursement decision in which financial elements (price, budget impact) are introduced; this sequential approach allows each member of the DRC to weight separately the scientific and financial elements in the reimbursement decision (5).

To respect the strict timelines imposed by the Transparency Directive, the procedure states that, if a Ministerial decision is not made within 180 days, the applicant obtains unconditional approval of his request. The decision is then entering into application on the first day of the month following the publication in the "Official Journal."

\section{Staff}

The DRC consists of thirty members. Its composition is as follows. (i) Twenty-two voting members: seven representatives from the Belgian universities; eight 
representatives from the sickness funds; four representatives from the physicians' associations; three representatives from the pharmacists' associations. Eight nonvoting members: four representatives from ministries (Ministry of Economic Affairs, Ministry of Budget, Ministry of Social Affairs, and Ministry of Public Health); one representative from the National Institute for Health and Disability Insurance (NIHDI); and two representatives from Pharma.be (organization of Belgian pharmaceutical companies) and one representative from Febelgen (organization of the Belgian generic pharmaceuticals industry).

The CRM is supported by staff from the NIHDI for the scientific and administrative evaluation of the submissions. Approximately sixteen full-time equivalents are charged with the preparation of the assessment files for the DRC.

\section{THE BELGIAN HEALTH CARE KNOWLEDGE CENTRE}

\section{Establishment and Legal Entity}

In the 1990s, many western European countries decided to establish an HTA agency, to assess the value for money of the many new healthcare interventions that boosted healthcare expenditures. In Belgium, the decision for the establishment of a similar HTA agency was made in the early years of the 21 st century.

The Belgian Health Care Knowledge Centre (KCE, which stands for Federaal Kenniscentrum voor de Gezondheidszorg / Centre fédéral d'expertise des soins de santé) was established by a program law in 2002 and started its activities in 2003 (1). At that time, the general director and a vice general director started to develop scientific working procedures and to recruit experts from different disciplines, including medicine, health economics, sociology, statistics, and data analysis. KCE published its first HTA reports in 2004.

$\mathrm{KCE}$ is semigovernmental agency that works independently from any particular governmental institution. The agency is entirely financed from public means.

\section{Mission}

The initial idea was to limit the mission of KCE to HTA. Because of the need for broader policy supporting research, additional domains were added to the objectives of KCE. The mission of $\mathrm{KCE}$ is to perform policy preparing research in the healthcare and health insurance sector. It gives advice to policy makers about how they can obtain an efficient allocation of limited healthcare resources that optimizes the quality and accessibility of health care.

The KCE has three domains of research: (i) Health technology assessment, (ii) Good clinical practice, (iii) Health services research. Health services research is defined in a broad sense, including research about equity and patient behavior.
$\mathrm{KCE}$ aims to produce analyses and studies in the different research domains in which decisions must be taken; to collect and disseminate objective information from registered data, literature, and current practice; and to develop high-level scientific expertise in the four research domains. Most of its activities are commissioned by the Ministry of Public Health and Social Affairs and by the National Institute for Health and Disability Insurance. However, KCE keeps the autonomy to decide on its year program, which will also include HTAs on topics suggested by other organizations and by the general public. KCE is not involved in the decision-making process itself, nor in the implementation of policy decisions. Currently, $\mathrm{KCE}$ is exploring ways to give methodological support to policy makers in the implementation of its recommendations, without actually taking over the actual responsibility of the implementation.

In the early years, $\mathrm{KCE}$ focused primarily on concrete health technologies in its HTAs. Since 2008, KCE started to produce also methodological reports that help on the one hand to standardize the methodology used for HTA in Belgium and on the other hand to help policy makers interpret the results of HTAs. Two examples of such methodological reports are the guidelines for pharmacoeconomic evaluations in Belgium (KCE report Vol. 78) and the report on the threshold values for cost-effectiveness ratios (KCE report Vol. 100). These methodological reports are considered important by policy makers and are, as such, considered an important additional mission of $\mathrm{KCE}$.

\section{Organization}

$\mathrm{KCE}$ has a Board that consists of decision makers, insurers, and providers. There are two members appointed by the Ministry of Public Health and two members by the Ministry of Social Affairs, the director of the Federal Public Service of Public Health and of the Federal Public Service of Social Affairs, the director of the NIHDI, three representatives for the Health Insurance funds (mutualities), two members appointed by the Council of Ministers, two representatives for the hospital sector, two representatives of the medical doctors, two members appointed by the social partners, one member appointed by the Chamber of representatives, and one member as commissioner of the government. The Board's president is appointed by the minister of Social Affairs and Public Health.

\section{Working Procedures}

Topic proposals for research at KCE can be submitted throughout the year by every citizen interested in health care. An active search for proposals is done March of each year by KCE. Then, a request for proposals is distributed through e-mail, press-releases, a message on the Web site. Table 2 presents the number of proposals submitted each year since the establishment of KCE according to their source. 
Table 2. Evolution of Topic Proposals According to the Source of Submission

\begin{tabular}{lrrrrr}
\hline & 2004 & 2005 & 2006 & 2007 & 2008 \\
\hline Ministry of Social Affairs and Public Health & 7 & 8 & 8 & 1 & 0 \\
NIHDI & 5 & 6 & 8 & 17 & 11 \\
Federal Public Service Public Health & 7 & 10 & 5 & 11 & 17 \\
Federal Public Service Social Security & 1 & 0 & 0 & 0 & 0 \\
Public Health Commission of the Chamber of Representatives & 5 & 0 & 0 & 0 & 0 \\
Universities or scientific institutions & 29 & 24 & 33 & 37 & 37 \\
Private organizations or individual citizens & 6 & 22 & 35 & 56 & 53 \\
Hospitals & 20 & 18 & 9 & 14 & 21 \\
International organizations & 0 & 2 & 2 & 2 & 2 \\
Non-federal governmental organizations & & & & 138 & $\mathbf{1 4 3}$ \\
Total & 80 & 90 & 100 & 138
\end{tabular}

NIHDI, National Institute for Health and Disability Insurance.

Table 3. Evolution of the Number of Reports and Budget of KCE Since 2003

\begin{tabular}{lcccccc}
\hline & 2003 & 2004 & 2005 & 2006 & 2007 & 2008 \\
\hline No. of topic proposals & 25 & 80 & 90 & 100 & 138 & 143 \\
No. of full-time equivalents & 9 & 25 & 31.5 & 36.6 & 39.4 & 40.6 \\
Budget spent $(\mathrm{x} € 1,000)$ & 2,541 & 3,722 & 4,441 & 5,673 & 6,448 & 6,912 \\
No. of approved reports & & 8 & 16 & 26 & 23 & 28 \\
\hline
\end{tabular}

KCE, Belgian Health Care Knowledge Centre.

Research topic proposals are evaluated once a year. The procedure starts in May. Each topic proposal is anonymous and evaluated independently by at least 4 people from the internal research staff. They score each proposal on the following four criteria: (i) is the topic within the scope of the mission of KCE and is it feasible to perform a study on the topic within reasonable time limits; (ii) can the results of the study lead to a significant improvement in the health of the population; or (iii) to a better allocation of healthcare resources; and (iv) will the results of the study be useful for the decision-making process.

For the thirty highest ranked topic proposals, a preproject fiche is developed. This preproject fiche is a rapid assessment of the available evidence on the topic and a first exploration of the possible methods for studying the subject. Research topics are planned and prioritized in collaboration with the members of the Board in October. For the short list of topics retained for the yearly program, a project fiche is developed. The project fiche contains a more extensive exploration of the methodology of the study (study protocol) and the data needed to perform the study.

Between twenty-five and thirty studies are performed each year. The yearly program is published on the Web site of KCE. In addition, the Minister of Public Health and Social Affairs regularly asks for an urgent study on a particular actual issue. These ad hoc studies are not included in the yearly program but usually get priority. The rising number of topic proposals went along with a rising number of reports and budgets, as shown in Table 3 .

In 5 years time, KCE published more than 100 study reports (over all domains of research).
Research projects are performed by internal experts (usually about 60 percent) or are commissioned to an external partner (about 40 percent), such as a university or another research organization. For studies for which an external partner is sought, a public tender is placed. The tender is published in the official "Bulletin of tenders" and on the Web site of KCE and mailed to people who declared an interest in the activities of KCE. The selection of the external partner is done by a jury, composed of internal and external experts. All external partners sign a confidentiality statement and a declaration of competing interests.

All projects are supervised by experts from the KCE. HTA reports contain specific recommendations for policy makers. The recommendations remain the responsibility of $\mathrm{KCE}$, even for projects performed by subcontractors. KCE staff also remains responsible for the quality control of the studies, the writing of the executive summary and the dissemination of the results to the policy makers and the general public. The KCE can rely on an external knowledge network that guarantees independent recommendations based on the state-of-the art scientific evidence. For each project, external experts from Belgium and/or from abroad are involved in the study. They help to pinpoint the hot issues as well as to identify the most recent developments in the field.

In the final stage of the report development, three external validators, from Belgium and/or abroad, are asked to critically review the report on its scientific validity. The validators can formulate their comments on the scientific approach and content and request minor or major modifications or they can reject or approve the report. They do not judge the recommendations and can therefore not request 
modifications to the recommendations. Conflicts of interest are disclosed by both the external experts at the start of a project as well as by the external validators during their validation work.

Before publication, each report is presented to the Board of KCE. The Board also has to approve the recommendations. Recommendations can for instance relate to the reimbursement of products or procedures, financing mechanisms, or organization of care. If more than 50 percent of the Board members approve the recommendations, the report can be published. A typical HTA takes between 6 and 18 months from start to publication on the Web site.

In addition to its regular activities, KCE is actively involved in the activities or is a member of international organizations such as the International Network of Agencies for Health Technology Assessment (INAHTA), the EUnetHTA Collaboration, CoCANPG, and OESO.

\section{Dissemination Activities}

The KCE has a legal obligation to make every report public within 1 month after approval by the Board. All reports are published on the Web site and can be downloaded for free (www.kce.fgov.be). Paper versions of the reports can be ordered at production price. Reports are written in English, with an executive summary in Dutch and French.

KCE also publishes press releases to disseminate the message to the general public as well as the professional community and organizes seminars to which people who expressed an interest in KCE activities through the Web site are invited. Press releases are regularly picked up by the national press. In 2007, for instance, KCE was mentioned in 450 articles in newspapers or journals. Experts are also frequently interviewed for radio or television.

\section{Staff}

The KCE has a permanent staff of approximately forty-seven people, accounting for forty-one full time equivalents (status in 2008). Of the forty-seven staff members, thirty (64 percent) are experts involved in the production of the scientific reports. There is one general director, one vice-director, one president, and two program managers. The remainder of the staff has an administrative function (seven) or supports the directors in their general management tasks (five).

The experts have different scientific and/or professional backgrounds, including medicine, economics, statistics, sociology, psychology, and law (Table 4). All experts have a university degree and some hold a $\mathrm{PhD}$. To guarantee the staff members' neutrality, experts are not allowed to perform any activities that could lead to potential conflicts of interest for their work as KCE experts.

$\mathrm{KCE}$ is a bilingual working environment. Staff members either have a French or Dutch mother tongue. Scientific research teams are usually composed of a mixture of both languages.
Table 4. Scientific Disciplines of Experts at KCE and Number of FTE

\begin{tabular}{lc}
\hline Data analysts & 2 \\
Economists & 9.4 \\
Medical doctors & 10.3 \\
Health services researchers & 8.3 \\
Total & 30 \\
\hline
\end{tabular}

KCE, Belgian Health Care Knowledge Centre; FTE, full-time equivalent.

All staff members are encouraged to follow continuing education, in Belgium and/or abroad. In addition, KCE organizes monthly seminars for its own and external experts, based on competencies and expertise of its own experts.

\section{CHALLENGES FOR THE FUTURE}

KCE has been very productive up until now. One of the challenges for the future will be to keep the quality of its research high, meanwhile coping with the continuous pressure to produce reports.

A more structural collaboration with external research groups would be useful, both for the efficiency (working procedures are known) and for the quality (selection based on expertise and scientific rigor) of the work.

The scientific procedures developed and refined between 2003 and 2005 are based on high-quality standards. They have proven their effectiveness. This does not mean, however, that they should no longer be subject to scrutiny. As new insights are gained in all research domains, the procedures might also need adaptation over time. It is therefore of utmost importance that the scientific experts stay up to date with the scientific developments in their field.

Although KCE evaluates the impact of its reports every year, the precise overall impact has never been measured according to a scientific methodology. In 2009, an external consultant will examine the impact of KCE reports on the healthcare sector and health policy.

KCE will continue to develop its international orientation. This should allow more efficiency in the production of HTAs and other reports and avoid duplication of work. The support to policy makers and potentially researcher organizations is an area that deserves further development. KCE should continue to develop methodological guidance reports for policy preparing research. In addition, KCE could give methodological support to policy makers upon request and present more systematically the results of its findings in the relevant governmental commissions. This would be a welcome new — or additional—challenge for the high-level and ambitious research staff of the organization.

In the context of these challenges for the future, KCE's independence from actual policy making should remain the cornerstone of the organization. 


\section{CONTACT INFORMATION}

Irina Cleemput, $\mathrm{PhD}$ (Irina.cleemput@ kce.fgov.be), Senior Health Economist, Belgian Health Care Knowledge Centre (KCE), AC Kruidtuin, Doorbuilding (10th floor), Kruidtuinlaan 55, 1000 Brussel, Belgium; Visiting Lecturer, Department of Public Health, K.U.Leuven, Kapucijnenvoer 35 (4th floor), 3000 Leuven, Belgium

Philippe Van Wilder, Pharm, MSc (Philippe.Van Wilder@riziv.fgov.be), Head, Drug Reimbursement Department, National Institute for Health and Disability Insurance, Tervurenlaan 211, 1150 Brussel, Belgium

\section{REFERENCES}

1. Belgian Health Care Knowledge Centre. Programmawet (I) van 24 december 2002, Title III, chapter 2. B.S./M.B. 31-12-2002.

2. Drug Reimbursement Committee. Royal Decree of 21 December 2001 (published 29 December 2001): Koninklijk besluit van 21 december 2001 tot vaststelling van de procedures, termijnen en voorwaarden inzake de tegemoetkoming van de verplichte verzekering voor geneeskundige verzorging en uitkeringen in de kosten van farmaceutische specialiteiten, B.S. 29 december 2001 // Arrêté royal de 21 décembre 2001 fixant les procédures, délais et conditions concernant l'intervention de l'assurance obligatoire soins de santé et indemnités dans le coût des spécialités pharmaceutiques, M.B. le 29 décembre 2001.

3. European Union. Council Directive 89/105/EEC of 21 December 1988 relating to the transparency of measures regulating the pricing of medicinal products for human use and their inclusion in the scope of national health insurance systems. OJ No L 40; 1989.

4. European Union. Directive 2001/83/EC of the European Parliament and of the Council of 6 November 2001 on the community code relating to medicinal products for human use. Official Journal L - 311, 28/11/2004. 2001. pp. 67-128.

5. Van Wilder PB, Dupont AG. Reimbursement of medicines in Belgium: Role of evidence-based medicine. Acta Clin Belg. 2009;64:120-128. 